\title{
DIVERSIDADE NA EDUCAÇÃO BÁSICA: POLÍTICAS DE SENTIDO SOBRE A FORMAÇÃO DOCENTE
}

\author{
Jane Adriana Vasconcelos Pacheco Rios* \\ Joana Maria Leôncio Nuñez** \\ Osvaldo Francisco Ribas Lobos Fernandez **
}

\begin{abstract}
RESUMO
O texto apresenta algumas notas teórico-metodológicas sobre diversidade na Educação básica através da investigação acerca de práticas educativas desenvolvidas pelo Programa Interinstitucional de Bolsas de Iniciação à docência - PIBID. Entendemos a diversidade como uma construção política, histórica e cultural das diferenças no espaço escolar que se materializa nos processos de vida-formação dos sujeitos envolvidos. Neste trabalho buscamos novos modos de produzir a docência no cotidiano escolar a partir da construção de dispositivos pedagógicos que tomam o tripé diversidade/ diferença/direitos humanos como elemento fundador da ação docente. Para este estudo, utilizamos a pesquisa-formação, organizada a partir de três etapas: Pesquisa Exploratório-etnográfica, oficinas formativas e elaboração de memorial de Formação. Os resultados deste trabalho apontam para outras políticas de sentido construídas sobre/ na formação docente a partir da (re) politização que a diversidade produz sobre as práticas educativas fundamentadas numa perspectiva intercultural a partir do encontro com a pedagogia das diferenças na escola.
\end{abstract}

Palavras-chave: Diversidade. Educação básica. PIBID. Formação Docente.

\section{ABSTRACT \\ DIVERSITY IN BASIC EDUCATION: POLITICS DIRECTION ON TEACHER TRAINING}

The paper presents some theoretical and methodological notes on diversity in basic education through research about educational practices developed by the InterInstitutional Program of Scholarships of Teaching Initiation - PIBID. We understand diversity as a political, historical and cultural construction of the differences in the school environment that is embodied in the processes of life-formation of those

\footnotetext{
* Doutora em Educação pela Universidade Federal da Bahia (UFBA). Pós-Doutora em Educação pela Universidade de São Paulo (USP). Professora Titular da Universidade do Estado da Bahia (UNEB). Professora Pesquisadora dos Programas de Pós-Graduação em Educação e Contemporaneidade (PPGEDUC/UNEB) e Educação e Diversidade (PPED/UNEB). Líder do Grupo de Pesquisa Docência, Narrativas e Diversidade (DIVERSO/UNEB). jhanrios1@yahoo.com.br

** Mestre em Educação pela Universidad Autónoma de Asuncón (UAA). Professora Auxiliar da Universidade do Estado da Bahia (UNEB). Pesquisadora do Grupo de Pesquisa Diadorim - Núcleo de Estudos de Gênero e Sexualidade e do grupo Anthropologicus (UNEB). Membro do Grupo de Pesquisa Candaces (UNEB).jmmleoncio@hotmail.com

*** Doutor em Ciências Sociais pela Universidade Federal da Bahia (UFBA). Pós-Doutor em Antropologia Urbana pela Columbia University of the New York City (EUA). Professor Titular do departamento de Educação da Universidade do Estado da Bahia (UNEB). Membro do Grupo de Pesquisa Diadorim - Centro de Estudos de Gênero e Sexualidade e do grupo Anthropologicus (UNEB). Pesquisador do grupo de pesquisa Candaces (UNEB) e do Grupo Interdisciplinar de Estudos sobre Substâncias Psicoativas (GIESP/UFBA). ribas.lobos@gmail.com
} 
involved. In this paper we seek new ways to produce teaching in school life through the construction of pedagogical devices that take the tripod diversity/difference / human rights as founding element of the teaching action. For this study, we use the formation-research, organized from three stages: Exploratory Research/ethnographic, formation workshops and elaboration of Formation memorial. The results of this study point to other policies of meanings built on/in teacher formation process from the (re) politicization that diversity produces on educational practices based on an intercultural perspective from the encounter with the pedagogy of differences in school.

Keywords: Diversity. Basic Education. PIBID. Teacher Formation.

\section{RESUMEN}

\section{DIVERSIDAD EN LA EDUCACIÓN BASICA: POLITICAS DE SENTIDO SOBRE LA FORMACIÓN DOCENTE}

El artículo presenta algunas notas teóricas y metodológicas sobre la diversidad en la educación básica a través de la investigación sobre las prácticas educativas desarrolladas por el Programa Interinstitucional de Becas de iniciación a la enseñanza - PIBID. Entendemos la diversidad como una construcción política, histórica y cultural de las diferencias en el espacio escolar que se materializa en los procesos de la vida y formación de los sujetos involucrados. En este trabajo buscamos nuevas formas de producir la docencia en la vida escolar a través de la construcción de dispositivos pedagógicos que toman el trípode diversidad/ diferencia /derechos humanos como elemento fundador de la acción docente. Para este estudio, utilizamos la investigación formación, organizada a partir de tres etapas: investigación exploratoria/etnográfica, talleres de formación y elaboración de memorial formación. Los resultados de este estudio apuntan para otras políticas de sentido construidas sobre y en la formación docente a partir de la (re) politización que la diversidad produce sobre las prácticas educativas fundamentadas en una perspectiva intercultural a partir del encuentro con la pedagogía de las diferencias en la escuela.

Palabras claves: Diversidad. Educación Básica. PIBID. Formación docente.

\section{Introdução}

A diversidade na educação tem tomado vários contornos nos últimos vinte anos. Políticas públicas, ações dos movimentos sociais, reinvindicações de sujeitos de direito vêm produzindo novas disputas de sentido sobre o tema. Pensar a diversidade no cotidiano da escola pública significa aqui refletir sobre a construção política, histórica e cultural das diferenças que constituem os espaços escolares, traduzidos, na maioria das vezes, nas inúmeras desigualdades sociais existentes em nossa sociedade.

No cenário brasileiro vivemos, atualmente, a chegada do novo Plano Nacional de Educação (PNE), em que a diversidade entra em discussão trazendo ainda para cena a invisibilidade das di- ferenças. Das vinte metas elaboradas pelo PNE, foram dedicadas apenas duas para a inserção da diversidade na educação, sendo estas voltadas para deficiência, povos do campo, indígenas e étnico-raciais. As discussões de gênero e sexualidade foram sucumbidas pelas disputas de sentido que envolvem a rede de poder que transversaliza o plano nacional. Juntamente ao PNE, recebemos a Base Nacional Curricular Comum (BNCC) em que igualdade e diferença se perdem na semântica do documento ao tentar trazer para a Educação Básica uma ideia de desenvolvimento de aprendizagem que sucumbe às práticas culturais dos sujeitos que compõem as escolas.

No cerne das políticas públicas da educação que envolve a diversidade e a formação docente, este 
artigo apresenta discussões acerca da Diversidade na Educação Básica a partir da ressignificação das práticas da docência desenvolvidas no cotidiano escolar. O trabalho baseou-se na Pesquisa-formação vivenciada no Programa Institucional de Bolsas de Iniciação à Docência (PIBID), desenvolvido através do subprojeto Diversidade, Docência e Pesquisa na Educação Básica, na Universidade do Estado da Bahia (UNEB), o qual tem por objetivo trabalhar com a construção da identidade docente a partir do desenvolvimento de práticas educativas em contextos de diversidade.

O texto está organizado a partir de algumas notas teóricas acerca da diversidade e suas relações semânticas/políticas com a diferença e as desigualdades sociais produzidas na educação. Assim como apresenta um desenho metodológico da pesquisa-formação desenvolvida com os bolsistas de iniciação e suas redes de sentidos produzidas acerca da Pedagogia da diversidade.

\section{Diversidade e Educação}

Os usos da diversidade exigem de nós uma postura relativista e de respeito às diferenças. $\mathrm{O}$ atual desafio da sociedade democrática está em como responder ao seguinte paradoxo: igualdade na diversidade, articulando política de igualdade com políticas de identidade. Lévi-Strauss (1976) - na memorável comunicação para a UNESCO denominada Raça e História, realizada no ano Internacional de combate ao racismo e à discriminação racial - exalta a diversidade etnorracial como a principal contribuição para o desenvolvimento e o progresso da humanidade, rechaça a supremacia racial e as bases da evolução humana, que concebia a sociedade branca europeia num patamar superior de desenvolvimento. Nesse artigo, mostra-se um antropólogo comprometido com a defesa dos direitos humanos e com o esforço teórico e humanístico de abandono da categoria de raça humana em direção à compreensão da diversidade étnica e cultural. Geertz (2001), no texto Usos da diversidade, questiona a posição de Levi -Strauss acerca do etnocentrismo, para o qual "pode ser até uma coisa boa" ter um conjunto de valores a enaltecer. Contudo, ele nos adverte que o etnocentrismo obscurece as diferenças e as assimetrias entre as pessoas, impedindo a possibilidade de mudança de mentalidade. Finaliza afirmando que há necessidade de ampliar e "fortalecer nossa capacidade de imaginação para poder apreender o que está diante de nós, que residem os usos da diversidade e o estudo da diversidade" (GEERTZ, 2001, p. 85).

$\mathrm{O}$ encontro e o diálogo entre culturas diferentes provocam mudanças de mentalidade em ambas. Por isso que a interculturalidade é uma das abordagens que consideramos mais apropriada, na educação, para lidar com a diversidade cultural presente nas sociedades complexas. Neste contexto, nossas reflexões teóricas acerca da diversidade ancoram-se em um campo polissêmico que atravessa sentidos entre igualdade/desigualdade, identidade/diferenças/ alteridade ou diversidade/direitos humanos. Estas relações produzem políticas de sentidos complexas que assumem configurações múltiplas no contexto educacional. O sentido é entendido aqui como "uma construção social, um empreendimento coletivo por meio do qual as pessoas lidam com as situações e fenômenos a sua volta" (RIOS, 2011, p. 38).

Historicamente, a escola constituiu-se como um grande espaço de padronização dos sujeitos, reforçando a legitimação de saberes, conhecimentos e padrões que pautaram as práticas curriculares e pedagógicas. Este cenário reforçou o apartheid, o desrespeito e a negação do outro a partir de várias formas e manifestações. A problemática da diversidade para a escola pública e para a sociedade brasileira está colocada desde o princípio do Estado Nação, uma sociedade composta com mais de trezentos grupos étnicos, duzentas línguas nativas/ indígenas no território nacional e tendo apenas o português como língua nacional já demonstra o lugar da diversidade no projeto desta nação.

Nos últimos trinta anos, verificamos a emergência de uma série de movimentos sociais (movimento negro, feminista, LGBT, HIV/AIDS, entre outros) que cobraram da educação uma reposta mais adequada aos velhos e novos desafios para a sociedade brasileira. A mobilização destes grupos originou algumas mudanças, como: alterações no currículo escolar com a introdução de disciplinas específicas; criação dos Parâmetros Curriculares Nacionais com apresentação dos temas transversais; aceitação do nome social para travestis e transgêneros em todo o território nacional. Essas 
iniciativas têm apontado para novas experiências, saberes e, em certa medida, têm refletido mudanças que vêm ocorrendo na sociedade brasileira com a maior aceitação e reconhecimento da igualdade como valor, mas, principalmente, a educação tem sido desafiada a transpor às representações hegemônicas sobre os papéis de gênero, cor/raça/etnia, classes sociais e o futuro dos avanços tecnológicos na sociedade brasileira.

Quando nos referimos à diversidade no ambiente escolar, imaginamos sujeitos desprovidos de poder, subalternizados pela história oficial nacional e com existência e reconhecimentos negados pelos livros didáticos e programas governamentais. A emergência de atores políticos, a partir da década de 1980, trouxe novas demandas à educação e à sociedade brasileira. A equação igualdade na diversidade, construída em salas de aulas por novas leis e projetos educacionais, numa dialética entre estado, sociedade e, sobretudo, pelos diferentes movimentos sociais, trouxe para a escola a necessidade da afirmação das diferenças, em uma perspectiva de enfretamento das desigualdades sociais.

Nesse contexto, a identidade e a diferença são tecidas e impostas em meio a uma relação de poder produzida nas relações sociais que (de)marcam o lugar ocupado pela escola na vida-formação dos sujeitos. Como construções sociais e culturais, as políticas de identidade na escola foram produzidas pela polarização, em que o par igualdade/diferença foi sempre posto em oposição, em uma construção binária: o igual (o ser) X o diferente (não-ser) (RIOS, 2011). Este binarismo é fortalecido nas práticas curriculares e pedagógicas vivenciadas no cotidiano escolar de forma redutora, sustentando estereótipos e discriminações. Fixar uma identidade como a norma é uma das formas privilegiadas de hierarquização das identidades e das diferenças. No caso da escola, a identidade posta no currículo é a norma e a outra é a desviante. A normalização é uma produção sutil de poder, determinando modelos, desvios, relações na sala de aula. Conforme Silva (2000, p. 83), "Normalizar significa eleger arbitrariamente - uma identidade específica como o parâmetro em relação ao qual as outras identidades são avaliadas e hierarquizadas. [...] A força homogeneizadora da identidade normal é diretamente proporcional à sua invisibilidade".
Muitas vezes isso é produzido pelo discurso da igualdade que silencia as diferenças, fundamentando processos de exclusão social. Na escola, a normalização foi traduzida na necessidade de tornar todos e todas sob o controle daqueles que ocupam o lugar da autoridade legitimada. O discurso "verdadeiro" do(a) professor(a), o conhecimento legítimo, exames, classificações, estabelecem, através das redes de poder, padrões "normais" para os estudantes. Em sala de aula, a normalização determina o que aprender, como aprender, o material didático, a proposta pedagógica, o que é ser "alguém" na vida; enfim, as políticas de sentidos e de formação que vêm sendo construídas na escola.

Por outro lado, o cotidiano escolar reflete e respira, hoje, as diferenças. É o lugar onde as diferenças coexistem de acordo com o pertencimento dos sujeitos a diversos grupos que assumem outras referências de saberes, valores e formação. De acordo com Silva (2000, p. 76):

Além de serem interdependentes, identidade e diferença partilham uma importante característica: elas são o resultado de atos de criação linguística. Dizer que são o resultado de atos de criação significa dizer que não são 'elementos' da natureza, que não são essências, que não são coisas que estejam simplesmente aí, à espera de serem reveladas ou descobertas, respeitadas ou toleradas. A identidade e a diferença têm que ser ativamente produzidas. [...] A identidade e a diferença são criações sociais e culturais.

Conforme a identificação com universos relacionais e identitários distintos, as pessoas produzem novas políticas de sentido na escola. Neste momento em que a reivindicação ao "direito à diferença" chega à escola e aos educadores e educadoras, contrapondo-se à perspectiva homogeneizante da instituição escolar, são imprescindíveis as reflexões sobre os sujeitos, as identidades que o constituem e sua relação como o outro. É neste lugar que encontramos a figura do(a) professor(a) em um espaço fronteiriço no processo de formação dos sujeitos. Esta produção é atravessada por tensões e conflitos em que o papel do(a) docente é fundamental para o deslocamento dos sentidos que retiram as práticas pedagógicas do gueto da normalização, potencializando os sujeitos para atuarem em relações de paridade e reciprocidade com o outro. 
É nesse espaço intermediário que o/a docente estabelece novas relações com a diversidade na escola, assumindo-se como sujeito híbrido capaz de negociar sentidos nas relações antagônicas e contraditórias vivenciadas na escola. Esta posição diante da educação nos coloca:

[...] face a face com o estranho, com a diferença, com o desconhecido, que não pode ser reconhecido nem apropriado, mas apenas conhecido em sua especificidade diferenciadora. Não se trata de reduzir o outro ao que pensamos ou queremos dele. Não se trata de assimilá-lo a nós mesmos, excluindo sua diferença. Trata-se de abrir o olhar ao estranhamento, ao deslocamento do conhecido para o desconhecido, que não é só o outro sujeito com quem interagimos socialmente, mas também o outro que habita em nós mesmos. (SOUZA; FLEURI, 2003, p. 68-69).

Assim, compreendemos que a identidade pode ser tomada como um ato performativo (SILVA, 2000) construído na vida social e nos posicionamentos dos sujeitos. É neste contexto que acreditamos que novas políticas de identidade vêm sendo re/feitas, delimitando outros territórios de sentidos na educação, mobilizados pelos sujeitos de direito.

De acordo com Gomes (2012), quanto mais se amplia o direito à educação, universaliza a educação básica e democratiza o acesso ao ensino, mais entram para o espaço escolar indivíduos antes invisibilizados ou desconsiderados como sujeitos de conhecimento. Segundo a autora, é imprescindível, no momento atual, uma análise sobre a educação brasileira em relação às duras condições materiais de existência vividas pelos sujeitos sociais e as dinâmicas culturais, identitárias e políticas. Para tal, chama atenção para a introdução da Lei $n^{\circ}$ $10.639 / 03,{ }^{1}$ que traz a obrigatoriedade do ensino de História da África e das culturas afro-brasileiras nas escolas da Educação Básica.

Em relação à questão da transposição pura e simples que as Leis podem assumir se forem traduzidas como mais uma disciplina nos currículos, sem provocar a devida ruptura epistemológica e cultural que a educação brasileira necessita, Gomes (2012) destaca o papel dos movimentos sociais de caráter identitário (mulheres, negros, indígena,

1 Altera a Lei no 9.394, de 20 de dezembro de 1996, que estabelece as diretrizes e bases da educação nacional, para incluir no currículo oficial da Rede de Ensino a obrigatoriedade da temática "História e Cultura Afro-Brasileira", e dá outras providências.
LGBT, quilombolas, povos do campo) para fazer face à realidade vivida nas escolas, tendo em vista a necessidade de reflexões teóricas e práticas pedagógicas que possam responder às demandas sociais e políticas destes grupos.

É no campo do direito humano e das políticas públicas que a diversidade caminha na educação, procurando investir no fazer cotidiano dos sujeitos, nos seus percursos e trajetórias de vida em busca do direito pelo conhecimento. É neste lugar que situamos a proposta de Pesquisa-Formação desenvolvida pelos(as) bolsistas de iniciação à docência do Programa Interinstitucional de Bolsas de Iniciação à Docência (PIBID), da Universidade do Estado da Bahia (UNEB), em duas escolas públicas de Salvador, a qual será sistematizada e discutida a partir das experiências vivenciadas nas referidas unidades escolares.

\section{Interculturalidade e Etnografia Escolar: pesquisa e formação na escola}

O projeto Diversidade, Docência e Pesquisa na Educação Básica nasceu da relação fronteiriça entre a pesquisa e a docência nos estudos acerca da diversidade produzidos pelo DIVERSO ${ }^{2}$ e pelo DIADORIM, ${ }^{3}$ numa perspectiva de desconstrução dos modelos homogeneizantes e binários de se relacionar com a vida-formação dos sujeitos no espaço escolar. Assim, o cotidiano escolar é investigado neste trabalho a partir das intervenções realizadas por bolsistas do PIBID 4 na Escola Municipal São Gonçalo do Retiro e no Colégio Estadual Polivalente do Cabula, ambas situadas na cidade de Salvador, no estado da Bahia.

O trabalho objetivou inserir os futuros(as) professores(as) em práticas de iniciação à docência, possibilitando a construção da sua identidade docente a partir dos diferentes espaços e tempos de formação construídos em contextos de diversidade. Esta experiência formativa ofereceu aos/às bolsis-

2 Grupo de Pesquisa Docência, Narrativas e Diversidade, vinculado ao Programa de Pós-Graduação em Educação e Contemporaneidade da Universidade do Estado da Bahia/ (UNEB).

3 Núcleo de Estudos de Gênero e Sexualidade da Universidade do Estado da Bahia (UNEB).

4 Os bolsistas do PIBID foram constituídos por estudantes das licenciaturas de Ciências Sociais e Pedagogia. 
tas de iniciação à docência uma aproximação com a prática docente, com a cultura organizacional da escola, bem como com a realidade educacional da Educação Básica, fortalecendo a articulação entre universidade, escola e sociedade. Entre as tarefas pedagógicas assumidas pelos(as) licenciados(as) destacam-se: o enfrentamento dos desafios presentes na educação básica; articular a formação da docência com outras áreas do conhecimento; contribuir para as reflexões acerca da diversidade que constitui a sociedade contemporânea.

Discutir o processo de formação docente vivido no cotidiano escolar foi um dos primeiros e grandes momentos de auto/formação para o grupo. Com o intuito de refletir acerca da equação filosófica e democrática da igualdade na diversidade no ambiente escolar, priorizamos observar a emergência dos conflitos e das vivências marcadas pelas diferenças que surgiram, espontaneamente, no cotidiano escolar. Os/as bolsistas foram instigados a refletirem a partir das seguintes questões iniciais: Quais diferenças vêm se traduzindo em desigualdades sociais no cotidiano das escolas? Qual a qualidade da educação oferecida? Como as diferenças de classe, étnica/raciais, gênero e sexualidade são tratadas na escola?

Para compreender a emergência dessas diferenças e/ou desigualdades sociais no cotidiano escolar, desenvolvemos um trabalho de Pesquisa-formação com os bolsistas do PIBID, fundamentada na abordagem qualitativa. Trata-se de uma pesquisa-ação inspirada teórica e metodologicamente na interculturalidade, comprometida com a construção de um ambiente escolar livre de racismo, xenofobia e trans/homofobia, voltado à produção de uma cultura do respeito e da paz.

Sabemos que a escola é um dos grandes loci de atuação do profissional docente, porém o fenômeno educativo não ocorre apenas no ambiente escolar. Por conta disto, a comunidade do bairro do Cabula foi tomada também como um espaço formativo para o grupo. Para isto, situamos a proposta nos estudos interculturais, para pensar a formação docente como lugar para potencializar diferenças e fundamentar processos formativos a partir da promoção das relações dialógicas e igualitárias entre pessoas e grupos que pertencem a universos culturais diferentes. Conforme Fleuri (2000, p. 78),
[...] A perspectiva intercultural de educação implica mudanças profundas nas práticas educativas [...] pela necessidade de oferecer oportunidades educativas a todos, respeitando e incluindo a diversidade de sujeitos e de seus pontos de vista. Pela necessidade de desenvolver processos educativos, metodologias e instrumentos pedagógicos que deem conta da complexidade das relações humanas entre indivíduos e culturas diferentes.

Os estudos interculturais baseiam-se na compreensão de que somos seres de discurso e nos posicionamos performativamente nos diversos contextos de significação que produzimos na vida. A prática educativa, nesta ótica, deixa de ser binária e passa por um processo de desconstrução e negociação de sentidos a partir de uma visão mais sistêmica, complexa e ecológica sobre o conhecimento. Além disto, possibilita a construção de um projeto comum, pelo qual as diferenças são dialeticamente incluídas.

Candau (2012) propõe quatro ações fundamentais para o trabalho na educação numa perspectiva intercultural: 1) desconstruir preconceitos e discriminações a partir de estratégias que modifiquem o caráter monocultural e etnocêntrico que, explicita ou implicitamente, estão presentes na escola e nas políticas educativas; 2) articular igualdade e diferença no nível das políticas públicas e das práticas pedagógicas; 3) resgatar os processos de construção das nossas identidades culturais tanto em nível pessoal como coletivo; e 4) promover experiências de interação sistemática com os "outros", favorecendo, sobretudo, o fortalecimento dos atores sociais que historicamente tiveram menor poder na sociedade.

Para isso, iniciamos com uma etnografia escolar, cujos registros foram feitos em diário de campo, os quais permitiram aos bolsistas analisar a realidade da escola e sua inserção na comunidade. Além disso, permitiu compreender os sentidos das ações, os níveis de significação e o contexto em que ocorre o processo ensino/aprendizagem, permitindo a elaboração de intervenções sobre a temática em estudo. Neste sentido, a etnografia é um dos métodos de pesquisa mais apropriados para investigar a realidade escolar, pois inclui tanto uma perspectiva macro quanto micro acerca do cotidiano, com vistas a uma "descrição densa" 
das cenas e situações do ambiente escolar para que os/as bolsistas pudessem conhecer o cotidiano em que o projeto seria desenvolvido. Conforme André (2003, p. 15):

A pesquisa etnográfica permite documentar o não documentado, isto é, desvelar os encontros e desencontros que permeiam o dia-a-dia da prática escolar, descreve as ações e representações dos seus atores sociais, reconstruir a sua linguagem, suas formas de comunicação e os significados que são criados e recriados no cotidiano do seu fazer pedagógico.

Diante disso, foi realizado um trabalho de descrição densa da realidade escolar, buscando os fatores socioculturais que afetam a dinâmica escolar. Os bolsistas puderam, neste período, conhecer a escola mais de perto a partir de suas três dimensões centrais: a institucional ou organizacional, a instrucional ou pedagógica e a sociopolítica/cultural. Neste sentido, a etnografia feita na escola foi de fundamental importância para o desvelamento das questões centrais que circundam o cotidiano escolar e suas relações com a diversidade. Com estas informações, os/as bolsista do PIBID puderam pensar nos usos da diversidade na escola e elaborarem intervenções pedagógicas acerca do tema.

Com o propósito de associar formação docente à investigação, a pesquisa-ação tomou os aspectos encontrados na etnográfica como elementos preliminares de análise e produção da mediação escolar. As questões centrais do cotidiano escolar foram transformadas em intervenções que, de forma circular, retornaram para novas análises e propostas para o fazer docente. As intervenções aconteceram no formato de Oficinas Pedagógicas a partir dos eixos temáticos da diversidade que emergiram da Etnografia. Por se tratar de uma pesquisa-ação e de formação/iniciação docente, buscamos analisar os usos da diversidade por nossos(as) bolsistas e a recepção dessas temáticas de formação/intervenção/ pesquisa na trajetória de vida e de formação dos(as) bolsistas de pedagogia e ciências sociais.

A partir dessas ações procuramos elaborar propostas de atuação dos bolsistas do PIBID, com vistas a um movimento de auto/formação do grupo para o trabalho com a diversidade na educação a partir de uma dimensão contracultural, desconstrucionista das representações hegemônicas, eman- cipatórias e reflexivas. O trabalho foi atravessado pelas reflexões formativas do grupo através da elaboração do Memorial de Formação, que trouxe as vivências e experiências dos(as) futuros(as) professores(as) com a diversidade na escola.

\section{Cartografias das diferenças e desigualdades sociais na escola}

Pelo fato de realizarmos nossas atividades em situações sociais cotidianas, acreditamos que é necessário pensar a formação docente em contextos reais, nos processos de identificações e diferenciações, processos constituinte de identidades e diferenças. É neste cenário que as diferenças e desigualdades sociais assumem um lugar preponderante na Pesquisa-formação, com a intenção de estabelecer outras políticas de sentido sobre a diversidade.

Dada a composição étnico-racial de nosso grupo de pibidianos(as) e, principalmente, das escolas visitadas, um dos marcadores sociais da diferença que mais emergiu do cotidiano escolar estudado foi a questão da negritude. Com isto, as propostas das Oficinas Pedagógicas voltaram-se, inicialmente, para esta questão, trazendo impactos positivos nas escolas e na comunidade que sediou o projeto. A experiência com o eixo temático nas escolas foi desafiador para os/as bolsistas, principalmente porque os espaços escolares não traziam a discussão em suas práticas curriculares cotidianas. Ainda que a localização das escolas esteja vinculada, histórica e/ou geograficamente, a terreiros de candomblé da cidade, mesmo que o corpo discente e docente ser constituído, em sua maioria, por negros, a temática étnica-racial chegava pontualmente nas aulas. A presença do preconceito, discriminação e negação de si esteve presente e circundou os/as bolsistas em todas as temporalidades formativas, como podemos observar nos relatos de Paula: ${ }^{5}$

[...] Para mim foi um desafio trabalhar com a temática, visto que a escola não desenvolvia projeto dessa natureza. No primeiro momento em sala de aula percebi que [...] a relação que os alunos tinham com o outro era de grande preconceito e discriminação. Ao observar os alunos em sala de aula e no recreio

5 Os nomes dos(as) bolsistas são fictícios, para preservar as identidades dos sujeitos envolvidos no estudo. 
presenciei situações de preconceito e discriminação entre dois alunos que se xingavam de preto e feio em suas brincadeiras. Diante das situações vivenciadas na escola, eu pude apresentar para a turma várias histórias da literatura afrodescendente, como: o cabelo de Lelê, a menina bonita do laço de fita, o menino marrom e outras que contribuíram com as crianças no processo de construção da identidade [...] Acredito que o trabalho desenvolvido na sala de aula contribuiu na vida dos alunos, uma vez que eles já diziam que eram negros. Já começavam a ensaiar um movimento de afirmação, difícil para o grupo e para o trabalho que estávamos desenvolvendo. A partir deste trabalho, a turma escreveu o livro Somos todos diferentes.

A bolsista buscou outros artefatos culturais para trazer à tona a questão do preconceito e da discriminação na escola, mostrando para os/as estudantes como isto afeta a formação de suas identidades. $\mathrm{O}$ uso da literatura e das escritas feitas pelas próprias crianças potencializou o trabalho formativo do grupo, em que o "diálogo das diferenças se impõe, apesar das dificuldades envolvidas em sua concretização no cotidiano das experiências educacionais" (CANEN; MOREIRA, 2001, p. 39). É relevante debater as diferenças e desigualdades historicamente produzidas entre diferentes grupos socioculturais, étnico-raciais, de gênero, orientação sexual, entre outros; a ideia de interculturalidade apoia-se justamente no entendimento de que na sociedade há diferenças e que elas são indispensáveis à convivência democrática para construir relações igualitárias entre os diferentes grupos socioculturais.

$\mathrm{O}$ que os estudos interculturais enfatizam é a necessidade de empoderamento daqueles(as) que foram historicamente inferiorizados(as), reforçando que as identidades sejam dinâmicas, abertas e plurais, fortalecendo a emancipação social de sujeitos e atores inferiorizados e subalternizados. Várias representações sobre o negro surgiram nas aulas dos(as) bolsistas e foram retomadas em suas memórias de formação, mas algo que aparece de forma enfática nas narrativas de formação é a desqualificação do negro a partir dos padrões de beleza. Cor, pele e cabelo foram pontos fortes na discussão e reflexão do grupo:

Em virtude de tantas atitudes preconceituosas no que diz respeito à cor e ao tipo de cabelo [crespos], jun- tamente com a minha colega do PIBID, começamos a trabalhar a valorização da origem e principalmente da cor e dos traços fisionômicos, fazendo as crianças perceberem a importância da cor e a beleza que eles possuíam. Enfim, trabalhamos muito a autoestima e, com o passar do tempo, as crianças foram adquirindo confiança em quem elas eram. As oficinas com espelho e os livros escolhidos com o tema foram ferramentas valiosas nas intervenções em sala de aula. Destaco o Menino Marrom e Menina Bonita do Laço de Fita, que foi o mais marcante e mais querido. (CARLA).

Outra questão desafiadora para estas crianças foi a valorização das características físicas da raça/etnia afrodescendente com relação ao cabelo, à pele, aos costumes, desconstruir estereótipos sobre cabelo 'ruim' e 'duro', explicar e valorizar a diferença, enfim, a diversidade. (MARIA).

$\mathrm{Na}$ auto/formação dos(as) bolsistas foi importante observar como estavam vivendo a experiência com a diversidade. Como reagiam aos seus próprios preconceitos e discriminações? Quais eram seus padrões de beleza? De que maneira percebiam, refletiam e teorizavam acerca das relações étnico-raciais? Os/as bolsistas foram convocados(as) a produzir novos sentidos sobre suas "certezas". O grupo foi chamado primeiro a olhar suas próprias diferenças e trabalhar o conflito para ressignificar as práticas pedagógicas na escola.

Lidar com as religiões de matrizes africanas constitui-se um aprendizado na formação dos(as) bolsistas. Esta foi uma demanda do grupo resultando do número de situações que foram levantadas na etnografia escolar, referentes a situações de preconceitos e desconhecimento em relação às tradições familiares e comunitárias dos(as) alunos(as).

Outra característica marcante da diversidade no PI$\mathrm{BID}$, na mesma turma do $2^{\circ}$ ano, é que a escola que atuo fica em um bairro que a religião predominante é o Candomblé, e existem na turma filhos(as) de Mães de Santo ou participantes das religiões afro-brasileiras. Os alunos falavam entre eles: 'a mãe dele disse que vai fazer uma macumba' ou 'Pró, ele disse que vai colocar meu nome na boca do sapo'. À medida que o projeto foi sendo desenvolvido e após discussões temáticas nas Reuniões de Formação e Oficinas nas Escola, pudemos retomar com os estudantes e professores a discussão da temática de diversidade religiosa, principalmente as de matrizes africanas. (LIA). 
No decorrer das oficinas com temáticas diversas, percebi que minha turma tinha uma grande aversão às praticas religiosas de origem africana. $\mathrm{O}$ Candomblé e a Umbanda foram diversas vezes classificados como 'Macumba', de forma negativa. (MARA).

Os/as bolsistas demonstraram, ao longo do percurso, dificuldades em lidar com as diferenças que atravessam a sala de aula em sua constituição. Em um primeiro momento, o lugar da tolerância foi pensado por eles(as) como alternativa para iniciar um processo de convivência entre alunos(as), porém perceberam na prática e na formação que a tolerância reforçava as desigualdades sociais. Segundo Gomes (2012), é necessária uma análise da educação brasileira que atente para as condições materiais de existência vivida pelos sujeitos sociais às dinâmicas culturais, identitárias e políticas. Neste sentido, a tolerância invisibiliza os sujeitos em seus direitos e em suas lutas por espaços que os tornem iguais na diferença. Conforme o bolsista Paulo,

Eles, assim como eu, têm aprendido que o segredo da diversidade não é a tolerância, mas o respeito. Compreendemos que nem sempre poderão entender todos os motivos aos quais seus colegas foram levados a algumas escolhas, mas que devem respeitar tudo aquilo que não os atingirem. Além disso, compreendemos que diversidade nem sempre é escolha, mas é próprio à humanidade. Depois de várias atividades sobre machismo e racismo, sobre liberdade sexual e gênero, perceberam em si próprios a reprodução de preconceitos. Não diria que a percepção foi o suficiente para uma mudança comportamental, mas ficaram cientes de ações realizadas como naturais. [...] O ensino da diversidade na escola tem sido importante para desvelar as ações mais simples, para tornar-se estranho ao comum e compreender as questões em sua raiz, não apenas o aparente nas suas relações. Dessa formação poderão dar um passo no reconhecimento do outro não apenas como um estranho, mas como diferente, uno.

Outra diferença que emergiu nesse processo de formação foi a questão de gênero e sexualidade. As ações do grupo de bolsistas com estas temáticas começaram com o lançamento do nome social, nas escolas, para travestis, transexuais e transgêneros pela Secretaria de Educação do Estado da Bahia. Em relação a esta questão, os/as bolsistas puderam realizar perguntas, tirar dúvidas e testemunhar um passo importante para o reconhecimento da orientação sexual e a identidade de gênero no ambiente escolar. Focalizar o preconceito e a discriminação a partir de um olhar atento às questões de classe, raça/etnia, gênero e sexualidade é uma forma de expor a estrutura desigual e excludente de nossas agências sociais, apontando outras formas de lidar com a diversidade humana.

Ainda que o tema sexualidades emerja com bastante força no cotidiano escolar, a questão ainda é tomada como um tabu nas escolas. Há um apagamento do corpo sexualizado na escola. A discussão fica situada no espaço privado, como uma problemática individual, esquecendo-se que a sexualidade não é apenas uma questão pessoal, mas também social e política. Segundo Moita Lopes (2013, p. 126-27),

[...] esse apagamento do corpo não quer dizer, entretanto que a escola não produza identidades corporificadas. Ao contrário, embora os/as professores/as estejam apenas começando a perceber a relevância dos discursos escolares na construção da vida social, a escola é uma das agências principais de (re)produção e organização das identidades sociais de forma generificada, sexualizada e racializada.

É nesse lugar de silenciamento do corpo e das questões de gênero que a discussão chega à escola básica e à formação dos(as) bolsistas. A discussão faz parte de todo um processo de afirmação e diferenciação que compõe a política de identidades já discutida neste texto, a partir da desconstrução de múltiplos discursos e sentidos sobre o sexo que normalizam e instauram "verdades". A partir destas construções, Dulce exemplifica o binarismo que a constitui e que a faz separar, discriminar e homogeneizar os papéis de homem e mulher. Meninos brincam de carro e meninas de bonecas - construção de sentido fixo produzido na vida-formação da bolsista.

[...] uma experiência vivenciada em sala de aula com crianças, quando, ao propor oficinas de brincadeiras, resgatando as suas práticas, essencialmente corporal [haja vista a massificação no cenário infantil atual do uso de jogos e brinquedos eletrônicos], adoto na condição de educadora uma postura que conserva e solidifica a concepção binária, na qual existem brincadeiras a serem utilizadas por meninos e outros por 
meninas. Neste contexto, recusei-me naturalmente, sem refletir, a participar juntamente com a turma de brincadeiras convencionalmente consideradas de meninos, como brincar de gude e de golzinho, limitando-me apenas a brincar de elástico, 5 marias, corda e roda. Sendo que na condição de educadora, objetivava nesta atividade desconstruir a concepção binária no mundo das brincadeiras. Contudo, as crianças, mostrando-se libertas de preconceitos, participaram satisfatoriamente, respeitando a predominância de meninos optando por jogar futebol, de todas as atividades. [...] O mais interessante de tudo é o que as crianças me ensinaram a superar meus próprios preconceitos [...] foi um estímulo no processo de construção e desconstrução de ações, comportamentos e conhecimento. (DULCE).

A bolsista mostra as limitações que tem com a discussão sobre o tema, apresentando suas contradições na formação. A linguagem e as práticas cotidianas tentam disciplinar os corpos a todo o momento, e as marcas deixadas na infância acompanham os sujeitos durante toda sua vida. Nesse contexto, acontecem o contato e a incorporação das ideias que consolidam ideologias de poder que se legitimam em detrimento do que se considera como desvio da sexualidade. Além dos discursos que se encontram arraigados em todo o contexto, outros recursos impõem um padrão a ser seguido, como: a postura de atuação dos(as) educadores(as), os conteúdos curriculares, as representações oriundas dos materiais didáticos, linguagens, símbolos, exigências de performances específicas dos sujeitos. Romper com as amarras que nos condicionaram a pensar a sexualidade como algo naturalizado, na qual o homem e a mulher foram construídos para satisfazerem mutuamente seus desejos pelo sexo oposto, representa um processo de desconstrução histórica e social. São políticas de sentido que constituem uma heteronormatividade compulsória acerca do feminino e do masculino. Conforme Louro (2000, p. 17):

Todas essas práticas e linguagens constituíram e constituem sujeitos femininos e masculinos; foram - e são - produtos de 'marcas'. Homens e mulheres adultos contam como determinados comportamentos ou modos de ser parecem ter sido 'gravados' em suas histórias pessoais. Para se efetivarem essas marcas, um investimento significativo é posto em ação: família, escola, mídia, igreja, lei participam dessa produção. Todas essas instâncias realizam uma pedagogia, fazem um investimento que, frequentemente, aparece de forma articulada, reiterando identidades e práticas hegemônicas enquanto subordina, nega ou recusa outras identidades e práticas, outras vezes, contudo, essas instâncias disponibilizaram representações divergentes, alternativas, contraditórias. [...] Se múltiplas instâncias sociais, entre elas a escola, exercitam uma pedagogia da sexualidade e do gênero e colocam em ação várias tecnologias de governo, esses processos prosseguem e se completam através de tecnologias de autodisciplinamento e autogoverno que os sujeitos exercem sobre si mesmos.

Nesse movimento de governar os sentidos constituídos na escola, encontramos os olhares sobre o papel da mulher na sociedade, que também teve destaque no trabalho desenvolvido pelos(as) bolsistas. Sales nos mostra resultados do seu trabalho:

Após quase três meses ter trabalhado a Lei Maria da Penha - Lei 11.340/2006, me deparei com uma situação bastante desafiadora quando uma aluna me chama, perguntando-me o seguinte: 'Pró, me ajude! Qual o órgão que posso procurar para denunciar meu colega que me xingou de piranha?' Confesso que, de imediato, levei um susto, mas depois tive gozo em saber que nossas aulas estão fazendo efeito, que está havendo aprendizado, pois aquela menina havia compreendido sobre a Lei e sua importância [...] (SALES).

A bolsista pôde contribuir para situações concretas na vida da estudante para que esta pudesse agir diante dos seus direitos como mulher, como individuo. A formação extrapola os muros da escola, ganhando os espaços sociais que o trabalho com a diversidade precisa alcançar. Percebemos que as ações ainda são pontuais com alguns temas, principalmente porque os/as bolsistas estão em processo de ressignificação de suas próprias identidades, fazendo-os retomarem "verdades", posicionamentos e práticas. Nesse formato acontecem o contato e a incorporação das ideias vinculadas a partir das práticas presentes no cotidiano escolar, as quais consolidam ideologias de poder que se legitimam hegemonicamente em detrimento das minorias.

[...] Na sala de aula deparei-me com as questões que envolvem a diversidade: um aluno do $2^{\circ}$ ano, com traços firmes do sexo feminino, cabelo grande amarrado em rabo de cavalo. Me referi a 'ele' como 
'ela'; os alunos corrigiram: 'é ele, pró!' Fiquei sem reação, mas logo tratei com naturalidade e passei a observar mais o aluno. Notei que ele era mais calado e tinha dificuldade para se relacionar com os colegas; os próprios colegas o tratavam como 'diferente'. Diziam: 'ele parece uma menina, pró!' Ele nunca reagia ou respondia aos colegas. (SALES).

Com essas experiências, os/as bolsistas puderam ampliar o repertório de sentidos acerca da identidade, diferença e desigualdade na escola. A compreensão da formação foi ampliada no momento em que vivenciaram suas próprias limitações com a temática da diversidade e colocaram seus sentidos em disputa e à deriva para que os atos formativos pudessem ser reconstruídos.

A despeito disso, João reflete sobre suas experiências e vivências antes e depois da formação no PIBID:

Venho refletindo muito sobre todo o histórico de minhas relações, todas as práticas que já tive com as mulheres que me interessei ou me relacionei. Desde então, tenho me sentido mal com muitos atos do passado, os quais havia naturalizado, e mesmo depois de perceber o quanto estava errado, não diagnostiquei a verdade sobre eles. A verdade é que fui [e talvez ainda possa ser] um assediador. Diversas vezes fui inoportuno, pressionei mulheres, forcei a barra. Não, meus relatos de machismo talvez nunca me levem a consequências sérias. Inclusive, na sociedade em que vivemos é até mesmo considerado normal, inofensivo. Somos educados a olhar para as mulheres como objetos em vitrines, a sexualizar qualquer uma de suas expressões. Somos sujeitos viris, capazes da máxima insistência para não aturarmos um não enquanto resposta. É do menino que rouba um beijo, que vence mulheres pelo cansaço, que o estupro é consequência. Fabricamos todos os dias assediadores, reproduzimos não em ampolas de vidro, mas nas experiências reais. Sobre como me sinto? Um ser vil, tentando ser regenerado, mas sem certezas, esperando que nunca mais venha agir dessa maneira.

De alguma forma, percebemos que as leituras que compõem o seu processo de formação, acompanhadas de um olhar atento para a realidade, conduziram esse estudante à narrativa acima. Junqueira (2009) vem trazendo essa discussão sobre a construção das masculinidades e declara que nossa formação escolar consente e até ensina, em todos os seus contornos institucionais, o menino a se com- portar, pensar, disseminar atitudes extremamente homofóbicas e misóginas. $\mathrm{O}$ autor acrescenta a esta discussão a construção equivocada do perfil do professor através das práticas que naturalizam essa violência na escola.

\section{Pedagogia da Diversidade: algumas considerações}

Para pensar a educação para a diversidade é necessário reconhecer a singularidade de cada ser, suas limitações e potencialidades no sentido de contribuir para o desenvolvimento de sua autonomia, reflexividade e crítica. Educar para a diversidade é a condição sine qua non para que nossas diferenças não sejam reproduzidas em desigualdades sociais, subalternidades e pobreza.

A sala de aula é o lócus privilegiado das diferenças e do aprendizado com a diversidade; para tal uma pedagogia inspirada na interculturalidade deve responder aos desafios das atuais sociedades complexas. Como lembrou Lévi-Strauss (1976), o progresso da humanidade é fruto da diversidade cultural, portanto cabe-nos criar uma ambiência nas escolas mais favorável ao ensino/aprendizagem sensível e de enfrentamento ao racismo, xenofobia, sexismo, trans/homofobia, credo religioso e todas as formas de discriminação que tendem a excluir pessoas, segregar e produzir mais desigualdade entre nós. Desta forma, as discussões acerca da diversidade na educação vêm adquirindo visibilidade e abrangência, tornando-se um momento de aprendizagem coletiva, no qual as pessoas estão lidando constantemente com as normas, os limites e a transgressão.

Um dos desafios do trabalho com a diversidade na educação tem sido politizar a vida social a partir da desconstrução dos sentidos im/postos e aprisionados em currículos e práticas pedagógicas homogeneizantes e fragmentárias. Desta forma, é necessária a apropriação de outros discursos que implicam em novos modos de ser e fazer docência na escola, reconhecendo a diversidade pessoal que nos individualiza em nossas qualidades, habilidades e performances, fundamentando novas políticas de identidade e direito às diferenças, como nos mostra Ana: 
[...] Descobri, através das vivências no 'chão da escola', que nos tornamos sensíveis aos problemas enfrentados e nos preparamos para atuarmos na docência. [...] Aprendi a apurar meu olhar acerca de situações preconceituosas, discriminatórias que foram emergindo no cotidiano escolar; fui aprendendo a construir estratégias para lidar com estas situações de conflito de valores, buscando media-los e torna-los lições de vida e de aprendizagem com a diversidade.

$\mathrm{Na}$ leitura de suas próprias experiências com as diferenças na escola, os/as bolsistas do PIBID trouxeram um movimento de politização de si no encontro com o Outro na construção de um projeto político/pedagógico que singulariza sujeitos em suas habilidades e performances. O processo de formação visou construir uma pedagogia para a diversidade que compreendesse os marcadores sociais da diferença no contexto escolar.

Enfim, a Pedagogia da Diversidade é a da singularidade, em que indivíduos são confrontados com seus limites, dificuldades e convidados a transpor seus erros, medos e intolerâncias em um aprendizado num mundo intercultural e democrático, onde possamos ver quem somos e ao mesmo tempo saber de onde percebemos uns aos outros, em uma perspectiva não etnocêntrica, mas com base numa relação dialógica, de respeito, solidariedade, cooperação e aprendizado mútuo.

\section{REFERÊNCIAS}

ANDRÉ, Marli Eliza D. A. de. Etnografia da prática escolar. 7. ed. Campinas, SP: Papirus, 2003.

CANDAU, Vera Maria (Org.). Didática crítica intercultural: aproximações. Petrópolis, RJ: Vozes, 2012.

CANEN, Ana; MOREIRA, Antônio Flávio Barbosa. Reflexões sobre o multiculturalismo na escola e na formação docente. In: (Org.). Ênfase e omissões no currículo. Campinas: Papirus, 2001. p. 15-43.

FLEURI, Reinaldo Matias. Multiculturalismo e interculturalismo nos processos educativos. In: CANDAU, Vera Maria (Org.). Ensinar e aprender: sujeitos, saberes e pesquisa. Rio de Janeiro: DP\&A, 2000. p. 67-81.

GEERTZ, Clifford. Os usos da diversidade. In: 2001. p. 68-85.

Novas luzes sobre a Antropologia. Rio de Janeiro: Zahar,

GOMES, Nilma Lino. Relações étnico-raciais, educação e descolonização dos currículos. Revista Currículo sem Fronteiras, v. 12, n. 1, p. 98-109, jan./abr. 2012.

JUNQUEIRA, Rogério Diniz, Homofobia nas escolas: um problema de todos. In: (Org.). Diversidade sexual na educação: problematizações sobre a homofobia nas escolas. Brasília, DF: MEC/Secretaria de Educação Continuada, Alfabetização e Diversidade/UNESCO, 2009. p. 13-52.

LÉVI-STRAUSS, Claude. Raça e História. Antropologia Estrutural II. Rio de Janeiro: Tempo Brasileiro, 1976.

LOURO, Guacira Lopes. Pedagogia da sexualidade. In: (Org.). O corpo educado: pedagogias da sexualidade. 2. ed. Belo Horizonte: Autêntica, 2000. p. 7-34.

MOITA LOPES, Luiz Paulo. Sexualidades em sala de aula: discurso, desejo e teoria queer. In: MOREIRA, Antônio Flávio; CANDAU, Vera Maria (Org.). Multiculturalismo: diferenças culturais e práticas pedagógicas. 10. ed. Petrópolis, RJ: Vozes, 2013. p. 125-148.

RIOS, Jane Adriana Vasconcelos Pacheco. Ser e não ser da roça, eis a questão! Identidades e discursos na escola. Salvador: EDUFBA, 2011.

SILVA, Tomaz Tadeu da (Org.). Identidade e diferença: a perspectiva dos estudos culturais. Petrópolis, RJ: Vozes, 2000 .

SOUZA, Maria Izabel Porto de; FLEURI, Reinaldo Matias. Entre limites e limiares de culturas: educação na perspectiva intercultural. In: FLEURI, Reinado Matias (Org.). Educação intercultural: mediações necessárias. Rio de Janeiro: DP\&A, 2003. p. 53-84. 